\title{
Tensile Strength of Maize Stalk and Husk single Cellulose Fiber
}

\author{
Addisu Workiye, Eyassu Woldsenbet ${ }^{*}$ \\ * Professor ,School of Mechanical and Industrial Engineering, \\ Addis Ababa Institute of Technology,Addis Ababa University,Addis Ababa, Ethiopia \\ Corresponding author email: Addwor1999@yahoo.com
}

\begin{abstract}
Maize stalk and husk fibers, as reinforcement, have recently attracted the attention of researchers because of their advantages over other established materials. They are environmentallyfriendly, fully biodegradable, abundantly available, non-toxic, non-abrasive, renewable, cheap, and have low density. Cellulose fiber extracted from maize stalk using retting process then its tensile strength and young modulus determined according to ASTM D3822. the fiber specimen were subjected to uniaxial tensile loading at a rate of $100 \mathrm{~mm} / \mathrm{min}$. Form the recorded load - elongation result ,tensile stresses and young modulus were determined. The maize stalk and husk fiber image were captured by biological microscope. Cross sectional width was measured using TS view software. The results were $44 \mu \mathrm{m}$ and $73 \mu \mathrm{m}$ respectively. The measured ultimate tensile stress for maize stalk cellulose fiber treated by $\mathrm{NaOH}$ purity $98 \%$ for 30 minutes ranged from 625Mpa to $1478 \mathrm{Mpa}$ (average $1184.04 \mathrm{Mpa}$ ), young modulus from 6728.99Mpa to $24107.94 \mathrm{Mpa}$ (average 16.27Gpa) and for maize husk fiber treated by $\mathrm{NaOH}$ the measured ultimate tensile stress ranged from 446.44Mpa to $1609.66 \mathrm{Mpa}$ (average 973.9Mpa), Young modulus from 3121.94Mpa to 13342..63Mpa (average 6.24Gpa).
\end{abstract}

Keyword- fiber, cellulose, retting, test, maize

\section{INTRODUCTION}

Agricultural residue is becoming a major source of fibers in the development of composites in building and packaging industries. Nature has given an immense source of natural fibers to human kind. Among them, plant fibers or cellulosic or vegetable fibers are dominating in building and packaging. Natural fibers possess a lot of favorable advantages over synthetic fibers in terms of cost, density, and bio-degradability, good acoustic, mechanical properties. Abundance, renewable, ease of separation, and carbon dioxide sequestration. Unlike brittle synthetic fibers, natural fibers are flexible and less likely to fracture during composite processing. This enables the fibers to maintain the appropriate aspect ratios to provide good composite reinforcement [1]. Maize is the global leading cereal in terms of production with 1,016 million metric tons (MMT) produced on 184 million hectares ( $\mathrm{M}$ ha) globally [2]. The increasing demand for maize and its global advance will imply by 2023 and maize will account for the greatest share (34\%) of the total crop area harvested [3].Corn stalks consist of a pithy core with an outer layer of long fibers. Currently, corn stalks are chopped and used for forage, left on the field, or baled for animal bedding [4]. Maize husk and stalk were assessed for their fiber characteristics and suitability for pulp and paper production. Fifteen (15) fibers were randomly selected and measured from each representative sample. It was observed that fiber length of maize husk was $1.37 \mathrm{~mm}$ and that of maize stalk was $1.52 \mathrm{~mm}$. The fiber diameter (D) was $30.19 \mu \mathrm{m}$ for each samples. The values of cell wall thickness and lumen width (d) for each sample were $8.82 \mu \mathrm{m}$ and $13.67 \mu \mathrm{m}$ respectively. Corn Stover typically consists of about 50 $\%$ stalk, $23 \%$ leaves, $15 \%$ cobs, and $14 \%$ husk. The stalks consist of an inner pith and outer rind which is the source for fibers [5].An Experiments were carried out to measure the tensile properties of maize stalk rind. The measured ultimate tensile stress ranged from 178.15 to $80.53 \mathrm{Mpa}$ (average $122.26 \mathrm{Mpa}$ ), elastic modulus from 35.01 to $11.38 \mathrm{Gpa}$ (average19.32Gpa), and tensile energy from 0.004 to $0.099 \mathrm{~J}$ (average 0.032J) [6].Alkaline treatment removed the lignin, cellulose, hemicelluloses and residues of the fibers surface maize fibers are treated with $15 \%$ diluted $\mathrm{NaOH}$ solutions at room temperature for $72 \mathrm{hrs}$.After the fibers washed several times with distilled water to remove excess $\mathrm{NaOH}$ from the fibers surface. Then the fibers neutralized with $2.5 \%$ diluted HCL [7].

Fiber $-\mathrm{OH}+\mathrm{NaOH}$----Fiber-O-NA $++\mathrm{H}_{2} \mathrm{O}$

Natural cellulose fibers were extracted from lignocellulosic byproducts using bacteria and fungi, mechanical and chemical methods [8]. Retting, the traditional process to extract fibers, the researcher uses bacteria and fungi in the environment to remove lignin, pectin and other substances. Sodium hydroxide is the most commonly used chemical for fiber extraction. [9]. Chemical concentration, temperature and duration of treatment are the main factors determining the quality of chemically extracted fibers [10]. the internodes of the maize stalk (hard outer layer) were separated from the pith, and heated for $90 \mathrm{~min}$ at $95^{\circ} \mathrm{C}$ under atmospheric pressure in $6 \mathrm{~g} / \mathrm{l}$ of $\mathrm{NaOH}$ aqueous solution in a ceramic pot-like container with high liquor to material ratio (1520:1). Finally, sheets of fibers were obtained based on the procedure described in the authors' previous study. The fundamental physical and mechanical properties of the maize fibers were summarized as follows. Density 
of $1.5 \mathrm{~g} / \mathrm{cm}^{3}$, average diameter of $145 \mu \mathrm{m}$ with a range of $60-220 \mu \mathrm{m}$, average tensile strength and elastic modulus of $141 \mathrm{MPa}$ and $6.3 \mathrm{GPa}$, respectively [11]. Moreover the maize stalk fibers were tested for tensile strength; fibers of uniform size were selected and tested in Hounsfield tensometer machine .The ultimate strength of the fibers was $152 \mathrm{Mpa}$ with average Young's modulus of $8582 \mathrm{Mpa}[12]$.

Table 1: Composition of maize stalk

\begin{tabular}{|c|c|c|c|c|}
\hline Fiber & Cellulose & Lignin & Hemicellulose & Referance \\
\hline Maize stalk & $38-42$ & $10-13$ & $21-23$ & G.C M Kumar etal \\
\cline { 2 - 5 } & $38-40$ & $7-21$ & 28 & N reddy etal \\
\cline { 2 - 5 } & 40.28 & 19.35 & - & I.Valchev \\
\hline
\end{tabular}

Axial tensile modulus, ultimate strength and failure strain of single fibers are determined for carbon and glass fibers. ASTM D3379-75 standard is followed and a number of fibers were tested for statistical analysis. The axial tensile moduli measured are $246.7 \mathrm{Gpa}$ and $93.3 \mathrm{Gpa}$, respectively and strength are $3031.6 \mathrm{Mpa}$ and 2035.9Mpa respectively for carbon and glass fibers [14].For the tensile testing of natural fiber, the closest applicable standard used was ASTM D 3822-01 the 'Standard for Tensile Properties of Single Fibers'. This ASTM standard was typically used to quantify the mechanical properties of textile fibers and threads, which are often from a natural source, such as flax or cotton [15].

Table 2: Gathered mechanical properties for target fibers from published literature [15]

\begin{tabular}{|c|c|c|c|}
\hline Name of fiber & Tensile strength (Mpa) & Tensile strain to failure (\%) & Young's modulus (Gpa) \\
\hline Abaca & $529-754$ & $1.0-3.5$ & $8.0-20.0$ \\
\hline & 500 & 7 & 12 \\
\hline & 764 & 3 & 30.1032 or 6.5164 \\
\hline & 764 & 2.6 & 6.2 \\
\hline Coir & 220 & $15-25$ & $4.0-6.0$ \\
\hline & $131-175$ & $15-40$ & 2.8 \\
\hline & $95-118$ & $23.9-51.4$ & 2.8 \\
\hline & 107 & 37.7 & $60-80$ \\
\hline Flax & $800-1500$ & $1.2-1.6$ & 54 \\
\hline & 1339 & 3.27 & 27.6 \\
\hline & $343-1035$ & $2.7-3.2$ & $10-30$ \\
\hline Jute & $400-800$ & 1.8 & $20-22$ \\
\hline & 533 & $1-1.2$ & 26.5 \\
\hline & $393-773$ & $1.5-1.8$ & 38 \\
\hline Sisal & $600-700$ & $2-3$ & $9-16$ \\
\hline & $568-640$ & $3-7$ & 15.2 \\
\hline & 458 & 4.5 & 15.2 \\
\hline & 363 & 5.2 & 70.5 \\
\hline Kenaf & 223 & 1.5 & 23.5 \\
\hline Hemp & $550-900$ & 1.6 & $30-90$ \\
\hline & 270 & 1 & 34 \\
\hline & $534-900$ & $1.6-3.5$ & 2.65 \\
\hline
\end{tabular}

The research was intended to expand information on fiber characteristics for better understanding of their complexity and potential in industrial use. Tensile properties of four types of individual cellulosic fibers, bamboo, kenaf, Chinese fir, and ramie, were measured by a custom-designed microtensile tester. Loaddisplacement curves for most individual fibers were found to be linear until failure. Average values of at least 30 individual fibers of bamboo, kenaf, Chinese fir, and ramie were 1685, 983, 908, and $1001 \mathrm{MPa}$ for tensile strength; 26, 19, 14, and $11 \mathrm{GPa}$ for tensile modulus; and 7.1, 5.4, 8.3, and 8.9\% for elongation at break, respectively. Cross-sectional areas of cell walls measured by confocal laser scanning microscopy were 117, 140, 217 , and $337 \mathrm{~mm}^{2}$, respectively. Among the fibers, bamboo had the greatest tensile strength and modulus, whereas the other three did not have any statistical difference. Ramie had the largest elongation at break and the lowest modulus. Elongation at break of kenaf was significantly smaller than that of the other fibers. [16].An 
improved Single Fiber Tensile Test (SFTT) for the natural fibers was depicted. Natural fibers have irregular shape, and are not uniform along the fiber length and also from one fiber to another. Applying the conventional method, which determine the fiber cross-section by measuring the fiber diameter using optical microscopy, will result in inaccurate properties of the natural fibers with large standard deviation (SD). In the proposed new SFTT method, an accurate cross-section area could be obtained from the Scanning Electron Microscope observation of a flat and clear fractured end surface of carefully selected tensile-tested fibers and calculated using imaging analysis. In many practical situations, the cross -sections of natural fibers are assumed to be circular and the projected width of the fiber is used to calculate a cross sectional area. Virk who suggested the use of a "fiber area correction factor" of 1.42 in the measurement of fiber modulus and strength to account for the overestimation of the fiber CSA by the diameter method. It is relatively easy to qualitatively understand this effect when considering the transverse observation of a non-circular cross section cylinder to obtain a "diameter" measurement. Indeed, in such a case the error in the estimation of the fiber CSA will increase with increasing aspect ratio of the major to minor axes of the fiber cross section, which will also result in higher values of "diameter" for fibers of equal CSA. Agricultural residue is becoming a major source of fibers in the development of composites. The abundant availability and accessibility of maize stalk fibers are the major reasons for an emerging new interest in sustainable technology.

\section{Material and Method}

\subsection{Maize Stalk and Husk Fiber Extraction}

Maize stalk fiber was selected based on abundance, accessibility, mechanical property, low cost. Maize stalk fiber was collected from a research plantation area at Ethiopia National Agricultural Research Institute Kulumsa branch. Water retting natural fiber extraction process used in this research work in order to gain fiber of grater uniformity and higher quality, Duration of retting process was 14 Days. Maize stalk Local Varity Harvested April, 12/2017 and Air dried for 15 days then cut in to internodes as shown on fig 1. Each node split into two pieces and immersed in to $\mathrm{NaOH}$ solution of $2.5 \mathrm{~g} / 10 \mathrm{~L}$ volume together with its husk as fig.2 show. After 14 days the lignin dissolved and cellulose fiber easily separated from the hemicellulose by hand then washed by water several times. The leafy outer shell/covering of an ear of maize is referred to as corn husk.

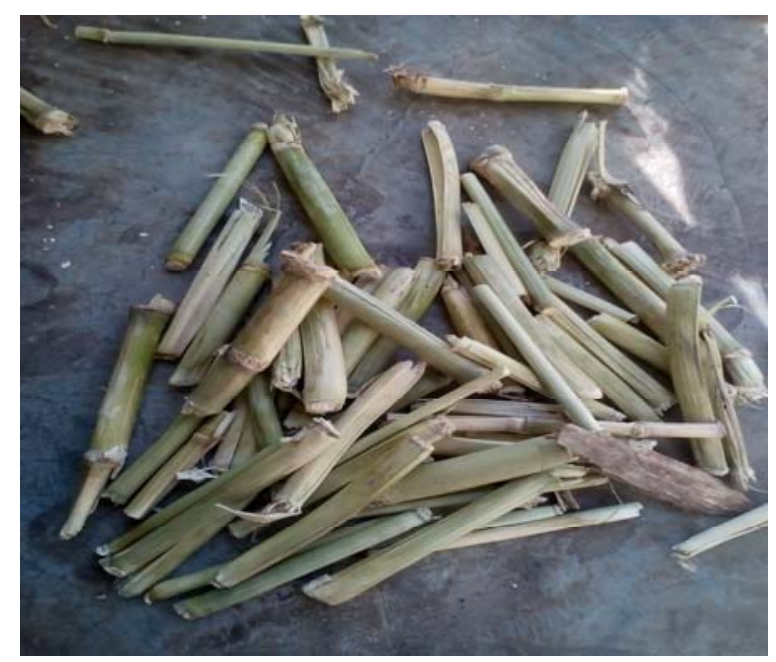

Fig 1. a) Maize stalk cut in to internodes 1

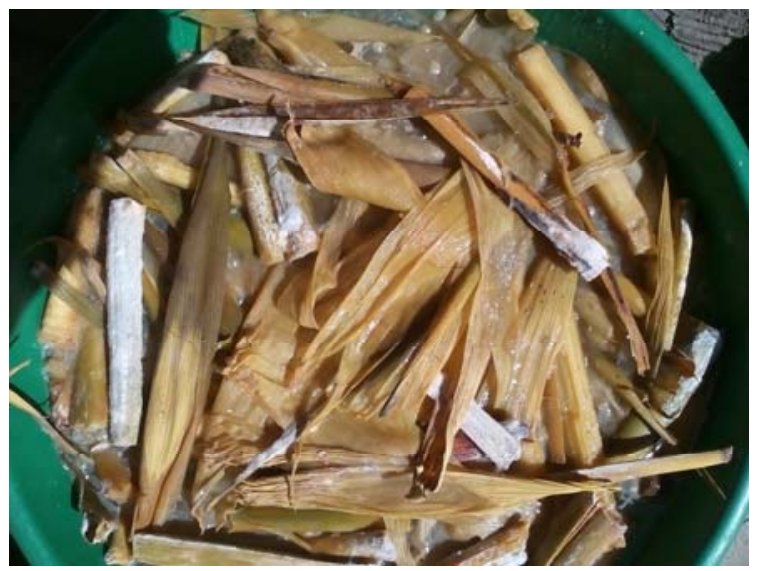

Fig.2. Maize stalk and husk in retting process 
Alkalization is a common pre-processing technique used on base natural fiber to remove hemicelluloses, fats and waxes that may reduce the interfacial strength when processed into composite form so the extracted cellulose fiber treated by $98 \%$ purity $\mathrm{NaOH}$ for $30 \mathrm{~min}$ shown on fig. 3 and fig .7 .

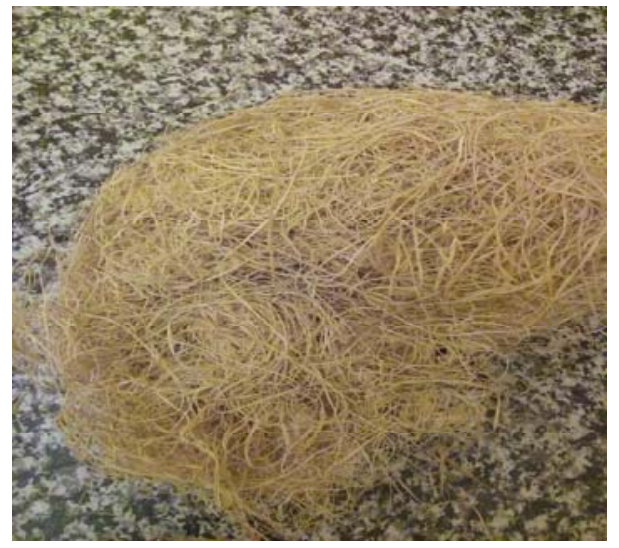

Fig.3 extracted fiber

\subsection{Fiber tensile strength test}

Single maize stalk cellulose fiber tensile strength test were conducted at research laboratory of Ethiopia Textile and Fashion Institute. Fiber tensile strength test of ten maize stalk single fiber and twenty maize ear husk single fiber conducted using fiber strength test machine as fig.5 shows with $10 \mathrm{~N}$ load cells, gauge length $25 \mathrm{~mm}$ and speed $100 \mathrm{~mm} / \mathrm{min}$ was used for the tensile test of a single fiber with ASTM D3822 standard. As fig. 4 shows breaking force result of ten different maize stalk cellulose fiber samples was considered. we determined average breaking force $2.49 \mathrm{~N}$ and average elongation $2.21 \%$.And also as fig.6 shows breaking force result of twenty different maize husk fiber samples were considered from the result we achieved average break force $5.75 \mathrm{~N}$ and average elongation $4.2 \%$.

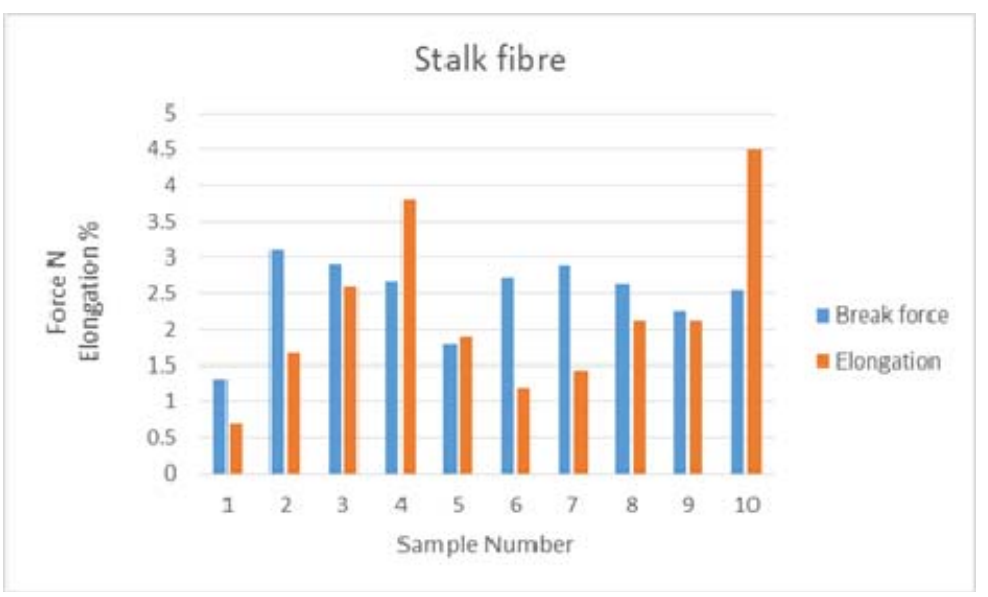

Fig. 4. Force and elongation of maize stalk cellulose fiber treated by $\mathrm{NaOH}$ purity $98 \%$ for 30 minutes

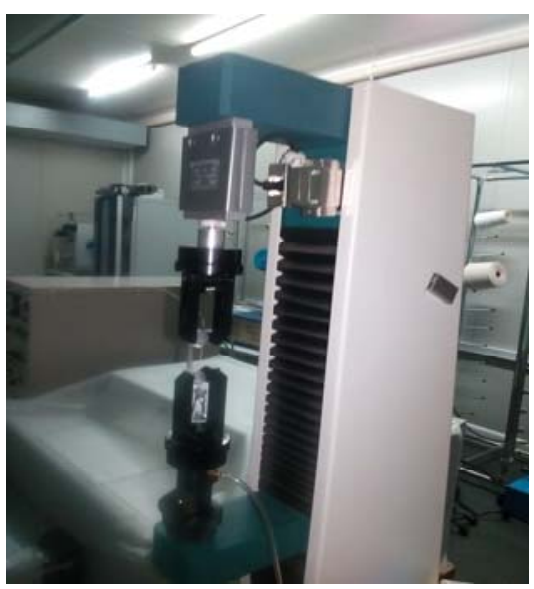

Fig.5. Tensile strength testing machine set up 


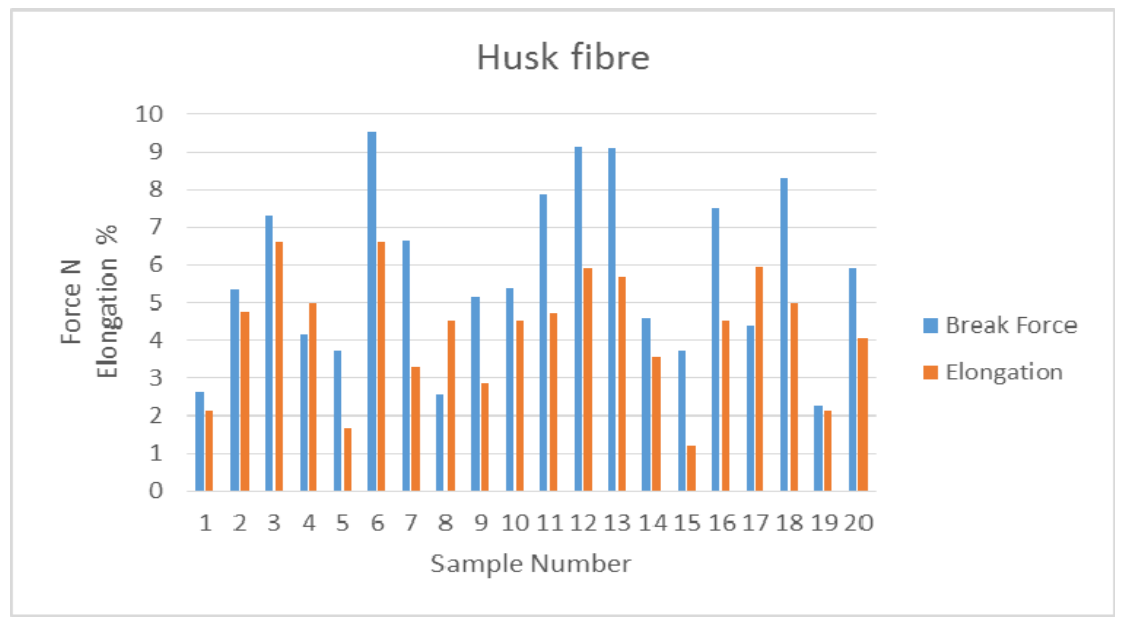

Fig.6. Force and elongation of maize husk fiber treated by $\mathrm{NaOH}$ purity $98 \%$ for 30 minutes

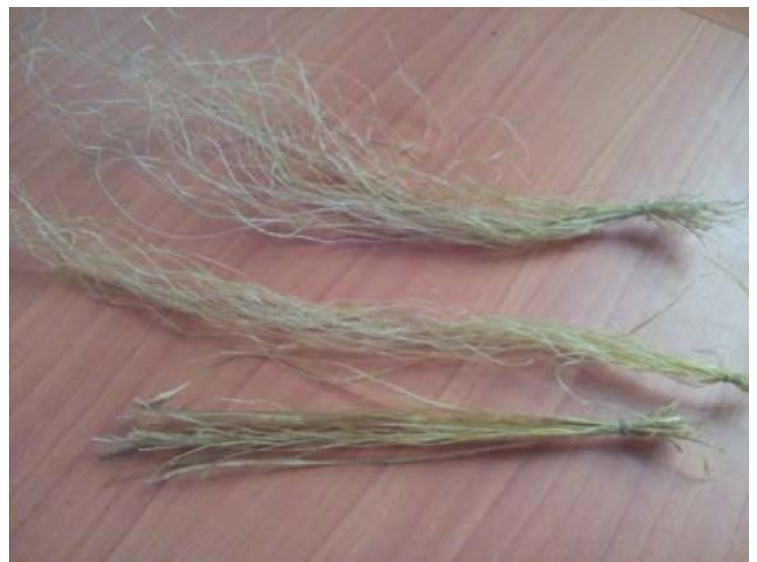

Fig. $7 \mathrm{NaOH}$ treated single fiber

\subsection{Fiber cross section}

As shown on fig.8 Fiber cross section of single maize stalk cellulose fiber was measured by biological microscope at Ethiopia Institute of Agricultural Research kulumsa laboratory.

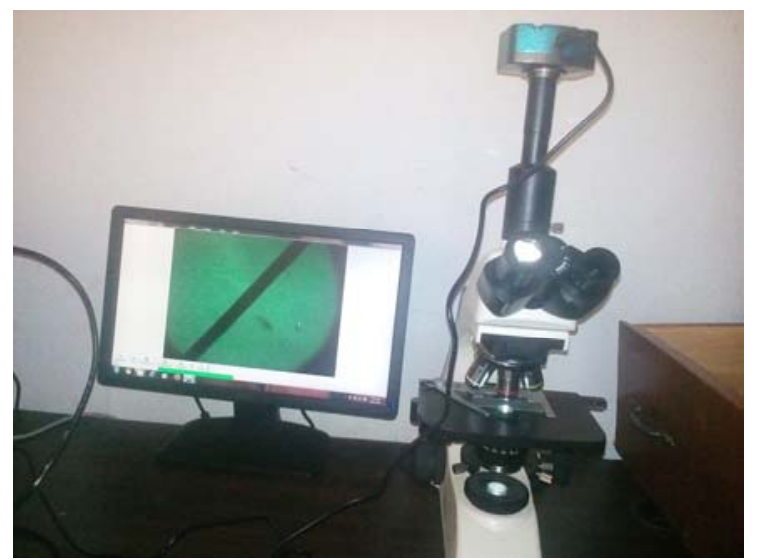

Fig.8. Biological Microscope 


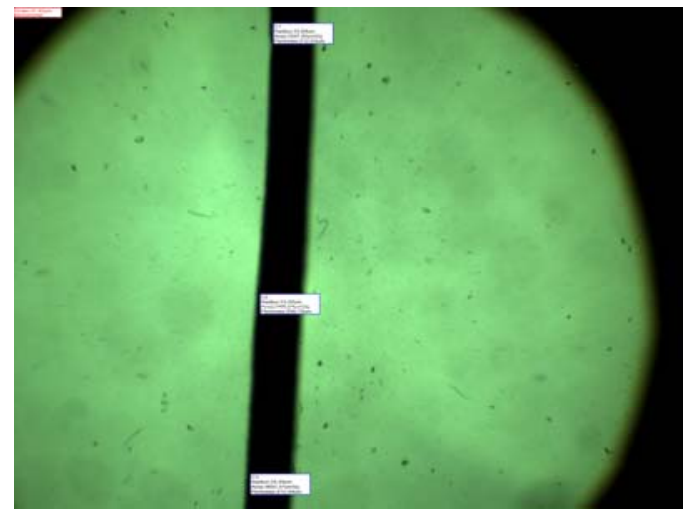

Fig.9. Width cross section Image of single maize stalk fiber

The cross section of $\mathrm{NaOH}$ treated maize stalk fiber of 40 samples randomly at top, middle and bottom side image captured by biological microscope and its cross section measured by TSview software. As shown on fig.9 ,average diameter $44 \mu \mathrm{m}$ were taken and similarly 20 samples maize husk fiber measured and average diameter of the fiber $73 \mu \mathrm{m}$ were taken in order to determine the tensile strength of the fiber. This is in good agreement with very recent results from a study of jute fiber diameter by (Virk) who suggested the use of a" fiber area correction "factor of 1.42 in the measurement of fiber modulus and strength to account the over estimation of the fiber cross section area by the diameter method.

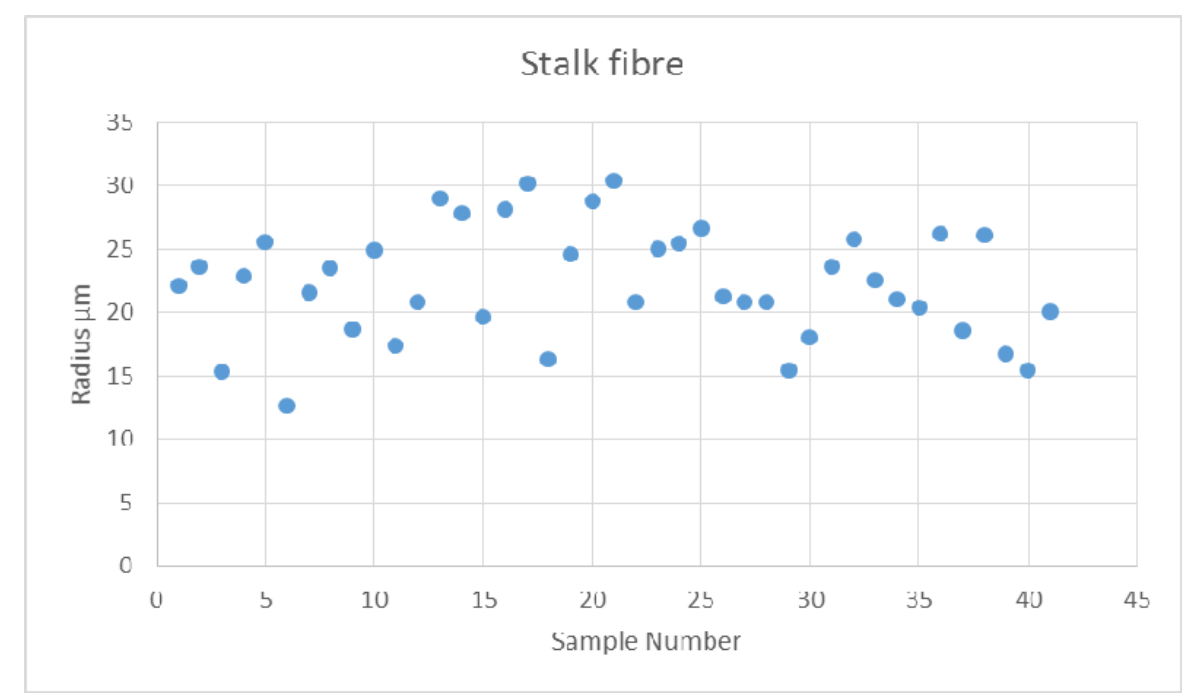

Fig.10. cross section of maize stalk fibre

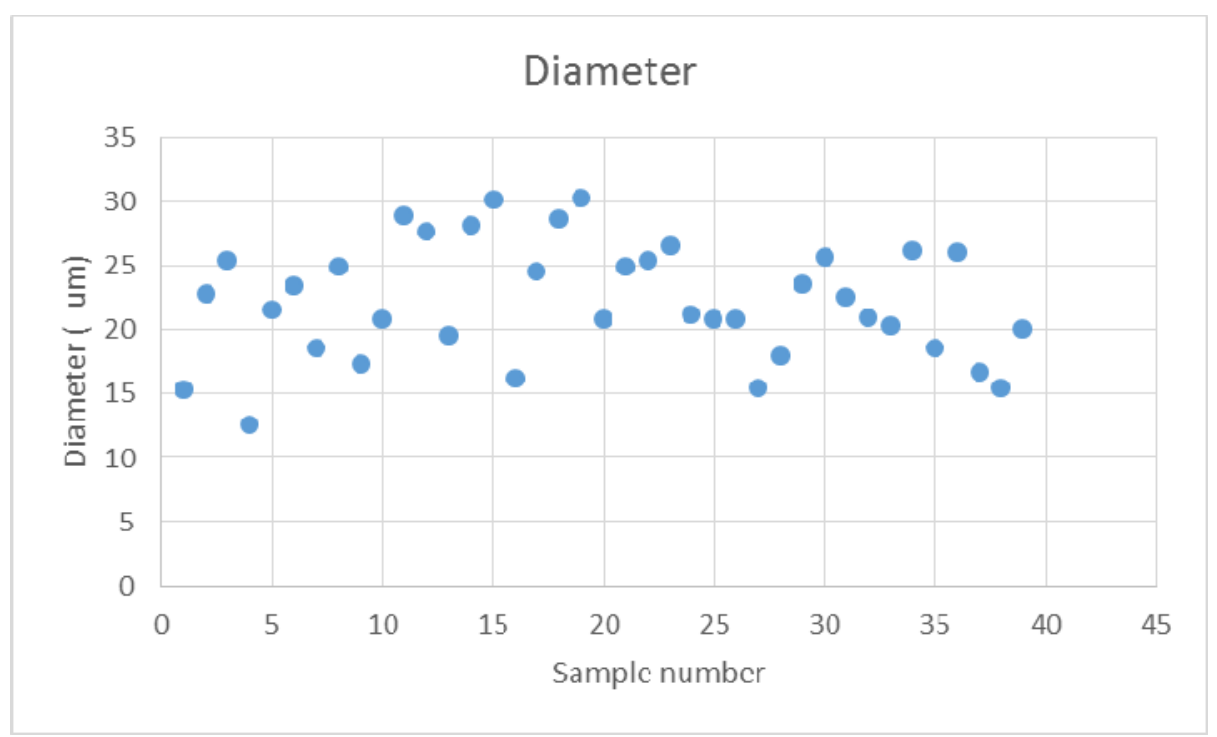

Fig.11 cross section of maize husk fibre 
For maize stalk single celluose fiber Cross section diameter range from $25 \mu \mathrm{m}$ to $60 \mu \mathrm{m}$ average $44 \mu \mathrm{m}$ and for maize husk celluose fiber Cross section range from $48 \mu \mathrm{m}$ to $90 \mu \mathrm{m}$ average $73 \mu \mathrm{m}$ and 1.42 cross sectional area correction factor was considered during calculation based on previous researcher as shown on fig. 10 and 11, respectively.

\subsection{Tensile Strength result of maize stalk single fiber}

As figure 12 shows, Breaking force result of ten different sample and cross section diameter of fiber $44 \mu \mathrm{m}$ were taken to determine the Tensile strength average 1184.04Mpa achieved.

$\sigma=\mathrm{F} / \mathrm{A}$

Where, $\sigma=$ Tensile Strength

$\mathrm{F}=$ Breaking force

$\mathrm{A}=$ cross sectional area,

\subsection{Young modulus result of single maize stalk fiber}

Young modulus determined from the relationship,

$\sigma=\mathrm{E} \varepsilon$

$\varepsilon=\gamma \mathrm{L} / \mathrm{L}_{\mathrm{O}}$

Where, $\mathrm{E}=$ Young modulus

$\sigma=$ stress

$\varepsilon=$ strain

$\gamma \mathrm{L}=$ Change in length

$\mathrm{L}_{\mathrm{O}}=$ Original length

As figure 12 shows, Elongation result of ten different sample and gauge length of $25 \mathrm{~mm}$ were taken to determine the strain. Young modulus $=$ stress $/$ strain, average $16268.5 \mathrm{Mpa}$ achieved.

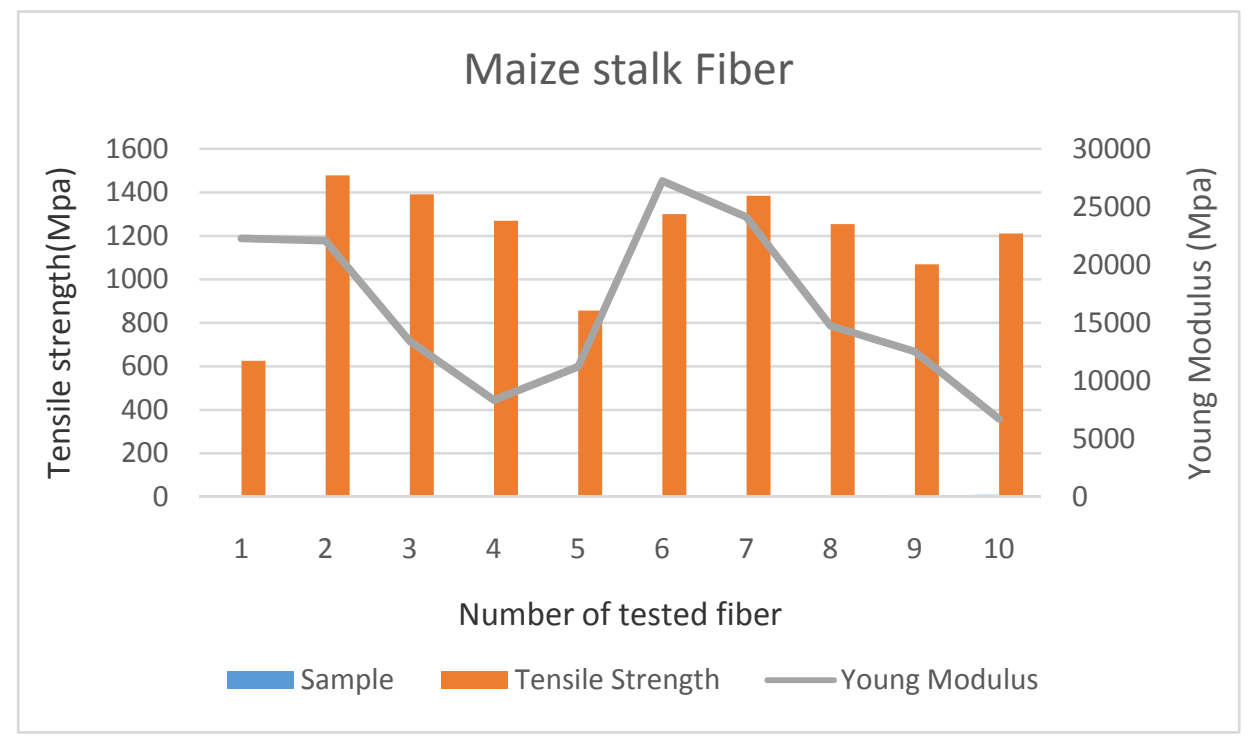

Fig.12.Tensile strength and Young modulus of Single Maize stalk cellulose fiber treated by $\mathrm{NaOH}$ purity $98 \%$ for 30 minutes

\subsection{Tensile strength result of maize cob husk single fiber}

As figure 13 shows, Breaking force result of twenty different sample and cross section diameter of fiber $73 \mu \mathrm{m}$ were taken to determine the Tensile strength and average 973.904Mpa achieved

\subsection{Young modulus result of single maize cob husk fiber}

As figure 14 shows, Elongation result of tewenty different samples and gauge length of $25 \mathrm{~mm}$ were taken to determine the strain and average $\mathbf{6 2 3 5 . 5 9 6 5 M p a ~ a c h i e v e d . ~}$ 


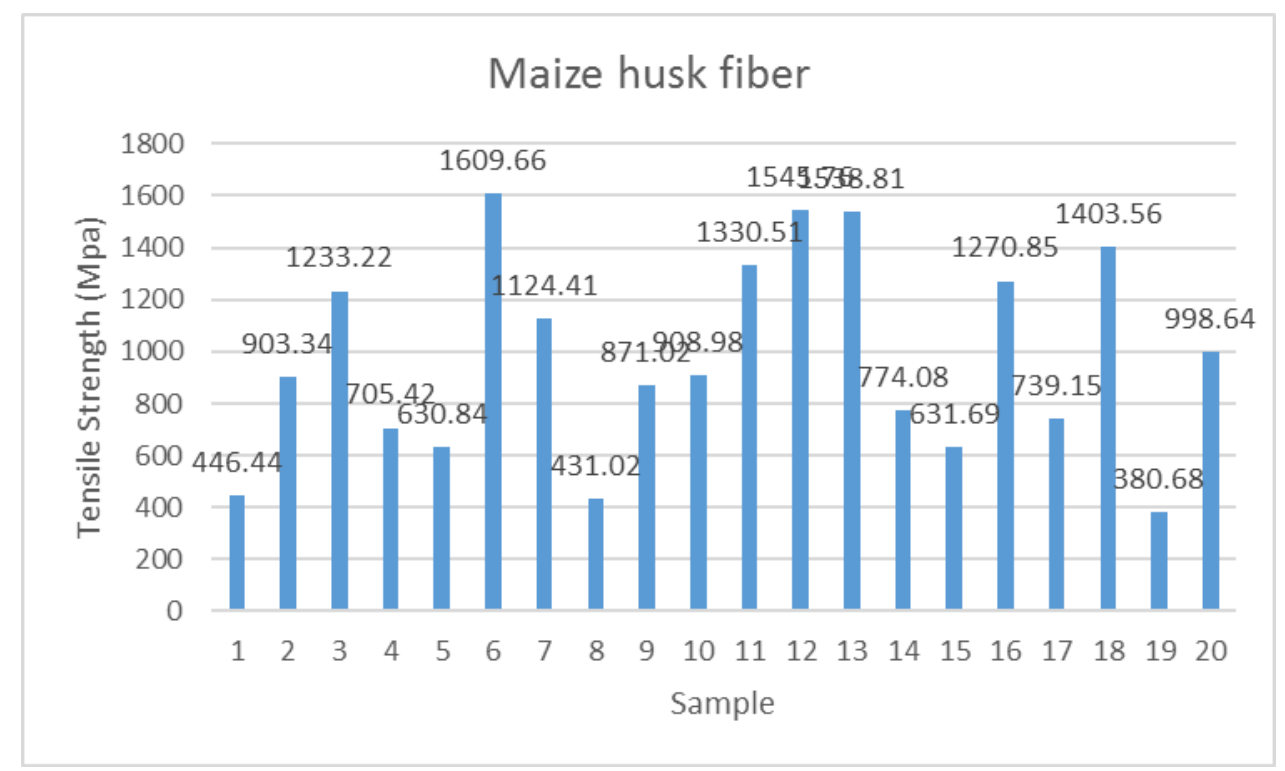

Fig. 13. Tensile strength of single Maize cob husk cellulose fiber treated by $\mathrm{NaOH}$ purity $98 \%$ for 30 minutes

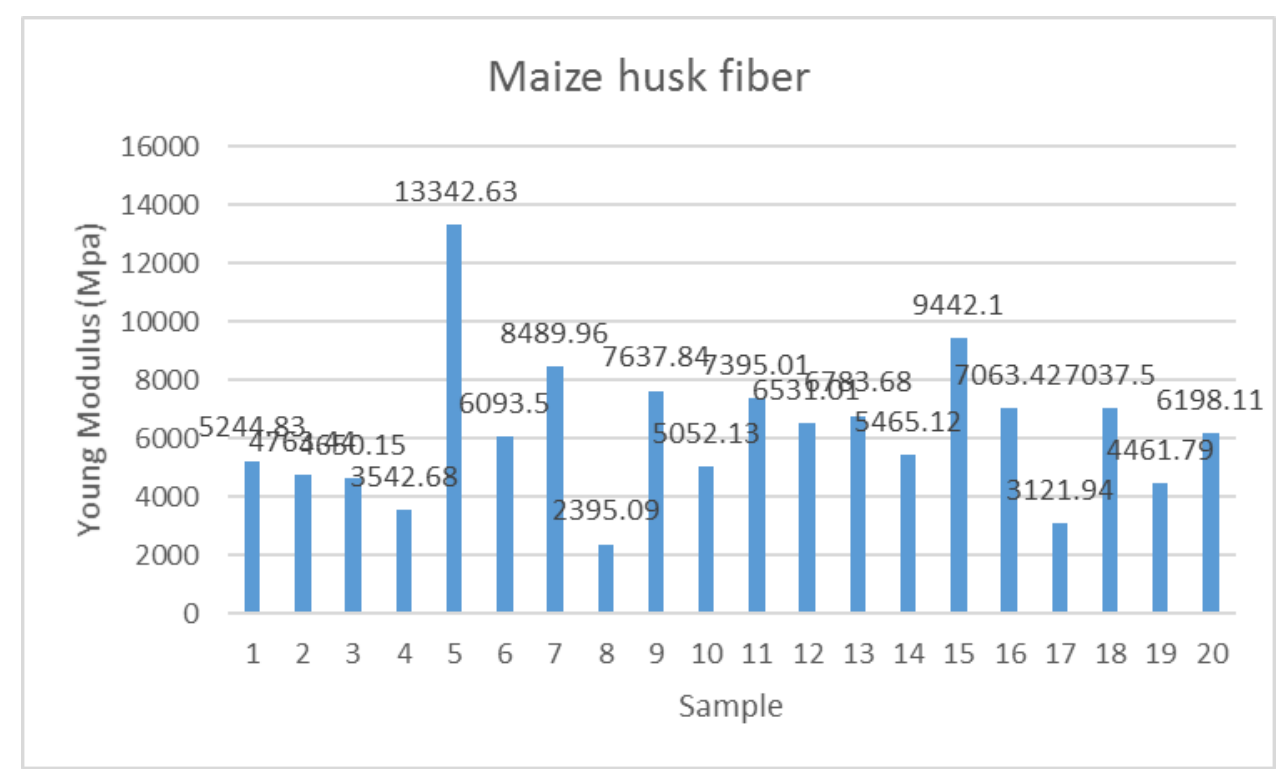

Fig.14. Young modulus of single Maize cob husk cellulose fiber treated by $\mathrm{NaOH}$ purity $98 \%$ for 30 minutes.

\section{Result and Discussion}

From conducting the tensile testing of the maize stalk fibers, graphs that offer a typical representation of the properties for $\mathrm{NaOH}$ treated maize stalk cellulose fiber and maize husk fiber can be viewed in Fig. 12, 13 and 14. These fibers were tested at room temperature. Cellulose fiber extracted from maize stalk using retting process then its tensile strength and young modulus were determined according to ASTM D3822 the fiber specimen were subjected to uniaxial tensile loading at a rate of $1.6 \mathrm{~mm} / \mathrm{sec}$. Average measured cross section diameter $44 \mathrm{um}$ for maize stalk fiber and 73um for maize cob husk fiber, cross sectional area correction factor 1.42 were used to determine its tensile strength and young modulus. From the recorded load - elongation result, tensile stresses modulus of elasticity were determined. The measured ultimate tensile stress for maize stalk cellulose fiber treated by $\mathrm{NaOH}$ purity $98 \%$ for 30 minutes ranged from $625 \mathrm{Mpa}$ to $1478 \mathrm{Mpa}$ (average $1184 \mathrm{Mpa}$ ), young modulus from 6728.99Mpa to $24107.94 \mathrm{Mpa}$ (average 16.27Gpa) and for maize husk fiber treated by $\mathrm{NaOH}$ the measured ultimate tensile stress ranged from $446.44 \mathrm{Mpa}$ to $1609.66 \mathrm{Mpa}$ (average 973.9Mpa), Young modulus from $3121.94 \mathrm{Mpa}$ to $13342.63 \mathrm{Mpa}$ (average 6.24Gpa). From the result, treated maize stalk cellulose fiber displays the largest average tensile stress and Young modulus then treated maize husk fiber. 


\section{Conclusion}

Maize stalk and husk harvested and dried at room temperature. The stalk cut into its inter nodes then split in to two then submitted in to water solution contain $2.5 \mathrm{~g} / 10 \mathrm{~L}$ then retted for 14 days at atmospheric temperature .Lignin dissolve in the solution and the cellulose fiber separated from hemicellulose using hand by pulling out. After cellulose fiber separated from the maize stalk and husk it was washed several times then dried. The extracted maize stalk and husk fiber treated by Chemical $\mathrm{NaOH}$ purity $98 \%$ for 30 minutes. Then tensile testing carried out based on ASTM D 3822 standard. From the result, it is possible to use as reinforcement for development geopolymer composite.

\section{References}

[1] Mohanty, A., Misra, M. and Drzal L. (2005) Natural fibers, Biopolymers, and biocomposites, CRC Press, New York

[2] FAOSTAT, 2013

[3] OECD-FAO, 2014

[4] Youngquist, J.A., English, B.E., Spelter, H., Chow, P., 1993 Agricultural fibers in composition penels.

[5] Ekhuemelo D.O. assessment of fibre characteristics and Suitability of maize husk and stalk for pulp and paper Production.

[6] Lixian Zhang etal,Tensile properties of Maize stalk rind.

[7] P.Baranitharan, G.Mahesh Alkali Treated Maize Fibers Reinforced with Epoxy Poly Matrix Composites, 2014.

[8] Narendra Reddy Biofibers from agricultural byproducts for Industrial applications

[9] G. Henriksson et al., Identification and retting efficiencies of Fungi isolated from dew-retted flax in the United States and Europe, Appl. Environ. Microb. 63 (1997), pp. 3950-3956. 14

[10] I. Doraiswamy and P. Chellamani, Pineapple-leaf fibers, Textile Progress 24 (1993) (1), pp.1-25.

[11] M. Dauda and M. Yoshiba, Processing and mechanical Properties of long maize fiber reinforced polypropylene Composites, Trans. MRS-J 26, 1083-1090 (2001).

[12] D. Saravana bavan 1 and G. C. Mohan Kumar Examination Of tensile strength and FTIR Features of maize Fibers Reinforced polymer composite, 2014

[13] Nreddy,Y.Yang,Innovative Biofibers from renewable Resources, 2015

[14] Prasanna Kumar Ilankeeran, Preetamkumar M. Mohite*, Sudhir Kamle Axial Tensile Testing of Single Fibres .

[15] Mark C. Symington, W. M. Banks* AND Opukuro David west.Tensile Testing of Cellulose Based Natural Fibers for Structural Composite Applications

[16] Ge Wang, Sheldon Q. Shi*, Jinwu Wang, Yan Yu, Shuangping Cao, Haitao Cheng Tensile properties of four Types of individual cellulosic fibers

[17] Wei Hu, Minh-Tan Ton-That, Florence Perrin-Sarazin, Johanne Denault an Improved Method for Single Fiber Tensile Test of Natural Fibers

[18] Virk AS, Numerical models for natural fibre composites with Stochastic properties, PhD thesis, University of Plymouth 2010. 